Gynäkologische Endokrinologie 2012 · 10:134 DOI 10.1007/s10304-012-0490-x

Online publiziert: 6. April 2012

(c) Springer-Verlag 2012

Deutsche Menopause Gesellschaft e.V.

Redaktion

Deutsche Menopause Gesellschaft e.V.

P. Stute, Bern

A.O. Mueck, Tübingen

\section{Originalpublikation}

Bidet M, Bachelot A, Bissauge E et al (2011) Resumption of ovarian function and pregnancies in 358 patients with premature ovarian failure. J Clin Endocrinol Metab 96:3864-3872 (Evidenzniveau: III)

Der Begriff prämatures Ovarialversagen (POF) bzw. prämature Ovarialinsuffizienz (POI) steht für einen hypergonadotropen (primären) Hypogonadismus bei Frauen $<40$ Jahren [1]. Die Prävalenz beträgt 1:250 bei Frauen <35 Jahren und 1:100 bei Frauen $<40$ Jahren. Ätiologisch werden 2 wesentliche Pathomechanismen unterschieden: - die beschleunigte Follikelatresie, z. B. aufgrund genetischer Aberrationen, einer Autoimmunerkrankung oder Zytostatikatherapie, und

- die reduzierte Steroidsynthese ohne Follikelverlust, z. B. aufgrund einer Mutation des Rezeptors für das follikelstimulierende Hormon (FSH).

Klinisch wegweisend sind die Amenorrhö, Sterilität und ggf. das Auftreten von klimakterischen Beschwerden mit einer Häufigkeit von 75\%. Bei 5-10\% der Frauen mit POF/POI wird über Spontankonzeptionen berichtet, die auf eine (vorübergehende) Erholung der Ovarialfunktion rückschließen lassen. Bisher gibt es keine klinischen, laborchemischen und/oder morphologischen Kriterien, mit denen die Wahrscheinlichkeit einer Spontanerholung der Ovarialfunktion abgeschätzt werden kann.

\section{Zusammenfassung der Studie}

Ziel dieser teils retro-, teils prospektiven Studie war es, die Prävalenz sowie poten-

P. Stute - Deutsche Menopause Gesellschaft e.V.

Inselspital Bern, Bern

\title{
Prämatures Ovarialversagen und die vorübergehende Spontanerholung der Ovarialfunktion
}

zielle prädiktive Marker für die vorübergehende Spontanerholung der Ovarialfunktion bei 358 Frauen mit idiopathischem POF zu ermitteln. Insgesamt zeigte sich bei 86 Frauen (24\%) eine Erholung der Ovarialfunktion; bei 77 (88\%) lag die Diagnosestellung des POF $<1$ Jahr zurück. Bei 15 Frauen $(4,4 \%)$ traten 21 spontane Schwangerschaften (16 Geburten und 5 Fehlgeburten) auf. Zu den signifikanten Prädiktoren für die Erholung der Ovarialfunktion zählten eine familiäre POF-Belastung, eine sekundäre Amenorrhö, die sonographische Follikelzahl sowie die Inhibin-B- und Östradiolkonzentrationen im Serum $(p<0,01$; multivariate Analyse nach dem Cox-Modell). Autoimmunerkrankungen, der Anti-Müller-Hormon(AMH)-Wert im Serum, der bioptische Nachweis von Follikeln und/oder genetische Veränderungen waren dagegen keine Parameter mit prädiktivem Wert. Die Autoren entwickelten einen prädiktiven Score zur Abschätzung der vorübergehenden Spontanerholung der Ovarialfunktion, um leichter Frauen mit POF identifizieren zu können, deren Ovarialfunktion sich wahrscheinlich intermittierend erholen würde. Der Score erlaubte eine Einteilung in 5 Gruppen mit zunehmender Wahrscheinlichkeit einer vorübergehenden Rückkehr der Ovarialfunktion innerhalb der folgenden $48 \mathrm{Mo-}$ nate (Gruppe 1: 0\%; Gruppe 5: 83\%).

\section{Kommentar}

Die Studie unterstreicht einmal mehr, dass der Begriff POF irreführend ist und der Ausdruck POI der hormonellen Situation besser gerecht wird. Die POI stellt eine intermittierende sowie unvorhersehbare
Ovarialfunktionsfähigkeit dar und ist von der echten prämaturen Menopause bzw. dem POF zu unterscheiden.

> Erstaunlicherweise besitzen der AMHSerumspiegel und das Vorliegen einer Autoimmunerkrankung in dieser Studie keinen prädiktiven Wert.

Dies ist möglicherweise auf die geringe Zahl an Frauen mit Autoimmunerkrankungen bzw. auf Datenlücken bei der AMH-Erfassung im untersuchten Kollektiv zurückzuführen. Dass die Inzidenz der vorübergehenden Ovarialfunktion unterschätzt wurde, ist außerdem aufgrund des gemischt retro- und prospektiven Studiendesigns nicht auszuschließen. Der interessante Ansatz der Entwicklung eines prädiktiven Scores muss in größeren Studienkollektiven validiert werden. $\mathrm{Zu}$ diesem Zweck wäre die Etablierung einer Datenbank von Frauen mit POF/ POI sinnvoll.

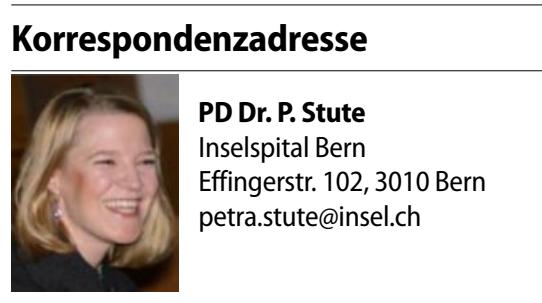

Interessenkonflikt. Die korrespondierende Autorin gibt an, dass kein Interessenkonflikt besteht.

\section{Literatur}

1. Maclaran K, Panay N (2011) Premature ovarian failure. J Fam Plann Reprod Health Care 37:35-42 (Review) 